\title{
A review of 640 Oral squamous cell carcinoma cases in Nigeria
}

\author{
Ahmed-Oluwatoyin Lawal ${ }^{1}$, Akinyele-Olumuyiwa Adisa ${ }^{1}$, Olajumoke-Ajibola Effiom ${ }^{2}$
}

${ }^{1}$ FMCDS. Senior Lecturer/Consultant, Department of Oral Pathology, College of Medicine, University of Ibadan, Nigeria ${ }^{2}$ FMCDS. Senior Lecturer/Consultant, Department of Oral and Maxillofacial Pathology \& Biology, College of Medicine, University of Lagos, Nigeria

Correspondence:

Department of Oral Pathology

College of Medicine, University of Ibadan

lawaloluwatoyin@gmail.com

Lawal AO, Adisa AO, Effiom OA. A review of 640 Oral squamous cell carcinoma cases in Nigeria. J Clin Exp Dent. 2017;9(6):e767-71. http://www.medicinaoral.com/odo/volumenes/v9i6/jcedv9i6p767.pdf

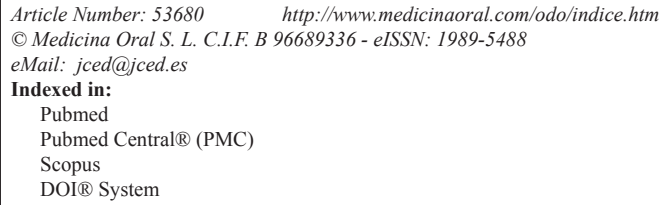

\begin{abstract}
Background: Oral squamous cell carcinoma (OSCC) is the most prevalent malignant neoplasm in the oral cavity and accounts for $70 \%$ to $90 \%$ of all oral malignant neoplasms. The aim of this study was to examine the demographic distribution of OSCC in five Tertiary Health centres in Nigeria.

Material and Methods: All cases diagnosed as OSCC during the period from 1970 -2014 were retrieved from the records of five teaching hospitals in Nigeria. Hematoxylin and eosin stained histological slides of all cases that had a diagnosis of OSCC were reviewed for confirmation and inclusion. Data from all the centers was collated at the University College Hospital, Ibadan by 2 researchers. The data was entered into and analyzed with the SPSS for Windows (version 20.0; SPSS Inc. Chicago, IL). Simple descriptive and comparative analyses were done, with the test of statistical significance set at $p \leq 0.05$.

Results: A total of 640 cases of OSCC were seen out of 1560 oral malignant neoplasms representing $41 \%$ of all the oral malignancies seen. The mean age of occurence of OSCC was $55.5( \pm 17.0)$ years and a peak age incidence in the sixth and seventh decades of life. OSCC occurred more in males $(60.9 \%)$ than females $(39.1 \%)$ with a male: female ratio of 1.6:1. The well differentiated OSCC with 309 (48.3\%) cases, was the most common grade, while the moderately differentiated and poorly differentiated OSCC accounted for $232(36.2 \%)$ and $92(14.4 \%)$ cases respectively

Conclusions: This study showed that OSCC is more common in males, most commonly seen in the 60-69 age group and the commonest site of occurrence was the mandibular mucosa. The well differentiated OSCC was the most common histology sub-type.
\end{abstract}

Key words: Oral squamous cell carcinoma, tongue, palate, mandible.

\section{Introduction}

According to World Health Organization, carcinoma of oral cavity in males in developing countries, is the sixth commonest cancer after lung, prostrate, colorectal, sto- mach and bladder cancer, while in females, it is the tenth commonest site of cancer after breast, colorectal, lung, stomach, uterus, cervix, ovary, bladder and liver (1). In the oral cavity, oral squamous cell carcinoma (OSCC) 
is the most prevalent malignant neoplasm and has been reported to account for $70 \%$ to $90 \%$ of all oral malignant neoplasms $(2,3)$. There is global variation in the incidence of OSCC with the Indian sub-continent presenting with particularly high incidence and prevalence, presumably, because of the predominant habits of chewing tobacco, betel quid and areca-nut (4).

OSCC occurs most often in males who are above 40 years of age $(5,6)$. Some authors have reported that up to $98 \%$ occurs above 40 years of age, with the incidence rising from an overall average of 3-4 cases per 100,000 per annum at all ages, to 100 cases per 100,000 per annum in those over 75 years of age (7). However, early exposure to tobacco use in western countries and habitual abuse of smokeless tobacco by teenagers in the Indian subcontinent has caused an increase incidence of OSCC amongst younger people $(7,8)$. More so, the increasing incidence of OSCC in young people and especially in those who do not smoke or use alcohol has been associated with increased infection by Human Papilloma Virus (HPV) occasioned by changing sexual preference of young people (9).

The aim of this study was to analyse the demographic distribution of OSCC in five tertiary Health facilities in Nigeria.

\section{Material and Methods}

All cases diagnosed as OSCC during the period from 1970 -2014 were retrieved from the records of the University Teaching Hospitals of Lagos, Ile-Ife, Ibadan, Port Harcourt, and Zaria. Hematoxylin and eosin stained histological slides of all cases that had a diagnosis of OSCC were reviewed for confirmation and inclusion. Researchers in each center retrieved records to obtain age, gender and location. The lesions were classified into; well differentiated, moderately differentiated and poorly differentiated according to broder's classification. Included parameters were documented according to a proforma designed by the researchers. Data from all the centers was collated at the University College Hospital, Ibadan by 2 researchers. The data was entered into and analyzed with the SPSS software version 20. Simple descriptive and comparative analyses were done, with the test of statistical significance set at $p \leq 0.05$. Ethical approval for the study was obtained from the UI/UCH Ethical Review Committee.

\section{Results}

A total of 640 cases of OSCC were seen out of 1560 oral malignant neoplasms representing $41 \%$ of all the oral malignacies seen at the 5 centres. OSCC occured with an age range of 4-108 years with a mean age of $55.5( \pm 17.0)$ years and a peak age incidence in the sixth and seventh decades of life both accounting for $43.0 \%$ of total number of cases seen. Table 1 shows age and gender distribution of OSCC from the five centres. OSCC was seen more in males $(60.9 \%)$ than females $(39.1 \%)$ with a male:female ratio of 1.6:1. The mean age for males was $54.8 \pm 16.4$ whilst that for females was $56.7 \pm 17.7$ but there was no statistically significant difference in the mean ages between males and females $(p=0.24)$. Table 2 shows the site distribution of OSCC; the mandible with $169(26.4 \%)$ cases was the most common site of occurrence followed by the maxillary gingiva with 109 $(17.0 \%)$ cases. The palate recorded $92(14.4 \%)$ cases whilst $59(9.2 \%)$ and $27(4.2 \%)$ cases ocurred in the tongue and floor mouth respectively.

Concerning Histologic grade, well differentiated OSCC with $309(48.3 \%)$ cases, was the most common grade, while the moderately differentiated and poorly differentiated OSCC accounted for 232 (36.2\%) and 92 (14.4\%)

Table 1: Age and gender distribution of OSCC cases.

\begin{tabular}{|c|c|c|c|}
\hline Age group & Male & Female & Total (\%) \\
\hline $0-9$ & 2.0 & 2.0 & $4.0(0.6)$ \\
\hline $10-19$ & 4.0 & 7.0 & $11.0(1.7)$ \\
\hline $20-29$ & 22.0 & 10.0 & $32.0(5.0)$ \\
\hline $30-39$ & 42.0 & 23.0 & $65.0(10.2)$ \\
\hline $40-49$ & 59.0 & 32.0 & $91.0(14.2)$ \\
\hline $50-59$ & 79.0 & 49.0 & $128.0(20.0)$ \\
\hline $60-69$ & 90.0 & 57.0 & $147.0(23.0)$ \\
\hline $70-79$ & 63.0 & 46.0 & $109.0(17.0)$ \\
\hline $80-89$ & 20.0 & 15.0 & $35.0(5.5)$ \\
\hline $90-99$ & 4.0 & 4.0 & $8.0(1.3)$ \\
\hline 100 & 2.0 & 0.0 & $2.0(0.3)$ \\
\hline missing & - & - & $8.0(1.3)$ \\
\hline Total (\%) & $395(61.7)$ & $245(38.3)$ & $640(100.0)$ \\
\hline
\end{tabular}


cases respectively (Table 3 ). The well differentiated OSCC occurred at peak age of 60-69 and had a mean age of $55.6 \pm 16.8$ while the moderately differentiated OSCC occurred at peak age of 60-69 had a mean age of $56.7 \pm 16.43$. In the same vein, poorly differentiated OSCC had mean age of presentation of $51.7 \pm 18.2$ and had a peak age incidence of 40-49. However, there was no statistically significant difference in age between histological grades of OSCC ( $p=0.43$, using one way anova). Although, OSCC occurred more in males in all 3 Histologic grades, the poorly differentiated OSCC had a much higher male: female ratio of 2.8:1, compared with 1.4:1 and 1.3:1 for well differentiated OSCC and moderately differentiated respectively.

Table 2: Site distribution of OSCC.

\begin{tabular}{|c|c|c|}
\hline Site & Number of patients & Percentage \\
\hline Mandible & 169.0 & 26.4 \\
\hline Maxilla & 109.0 & 17.0 \\
\hline Antrum & 55.0 & 8.6 \\
\hline Buccal mucosa & 46.0 & 7.2 \\
\hline Palate & 92.0 & 14.4 \\
\hline Tongue & 59.0 & 9.2 \\
\hline Floor of mouth & 27.0 & 4.2 \\
\hline Lip & 33.0 & 5.2 \\
\hline Gingiva & 22.0 & 3.4 \\
\hline Metastatic disease & 2.0 & 0.3 \\
\hline Submandibular gland & 4.0 & 0.6 \\
\hline Parotid & 8.0 & 1.3 \\
\hline Face & 5.0 & 0.8 \\
\hline Total & 631.0 & 98.6 \\
\hline missing & 9.0 & 1.4 \\
\hline & 640 & 100.0 \\
\hline
\end{tabular}

Table 3: Sex, age and site distribution according to histologic grade.

\begin{tabular}{|c|c|c|c|c|c|}
\hline Histologic grade & No $(\%)$ & $\mathbf{M} / \mathbf{F}$ & $\begin{array}{l}\text { Age range/ } \\
\text { mean Age }\end{array}$ & Peak age & Commonest sites (\%) \\
\hline Well Diff & $309(48.3)$ & $\begin{array}{c}\mathrm{M}, 183(59.2) \\
\mathrm{F}, 125(40.5) \\
\mathrm{M}: \mathrm{F}=1.4: 1\end{array}$ & $\begin{array}{c}9-100 \\
55.6 \pm 16.8 \\
\text { Median }=60.0\end{array}$ & $60-69$ & $\begin{array}{c}\text { Mand (28.5) } \\
\text { Palate (15.2) } \\
\text { Max (13.9) }\end{array}$ \\
\hline Moderately Diff & $232(36.3)$ & $\begin{array}{c}\mathrm{M}, 133 \\
\mathrm{~F}, 99 \\
\mathrm{M}: \mathrm{F}=1.3: 1\end{array}$ & $\begin{array}{c}12-94 \\
56.7 \pm 16.43 \\
\text { Median=58.0 }\end{array}$ & $60-69$ & $\begin{array}{c}\text { Mand (24.1) } \\
\text { Maxilla (17.2) } \\
\text { Palate (14.2) }\end{array}$ \\
\hline Poorly Diff & $92(14.4)$ & $\begin{array}{c}M, 68 \\
F, 24 \\
M: F=2.8: 1\end{array}$ & $\begin{array}{c}4-90 \\
51.7 \pm 18.2 \\
\text { Median }=50.0\end{array}$ & $40-49$ & $\begin{array}{c}\text { Mand (26.1) } \\
\text { Max (28.3) } \\
\text { Palate (12.0) }\end{array}$ \\
\hline missing & $7(1.1)$ & & & & \\
\hline
\end{tabular}

$\mathrm{M}=$ male, $\mathrm{F}=$ female, Mand=mandible, $\mathrm{Max}=$ maxilla, diff=differentiated. 


\section{Discussion}

Oral malignant neoplasms constitute a significant global health problem with reports signifying that they are the sixth most common malignancies worldwide and, together with malignancy of the pharynx, are the third most common malignancies in the developing world (10). The finding of this study that OSCC constitutes $41 \%$ of all oral malignancies was in sharp contrast to most previous studies which showed that OSCC accounts for $70-95 \%$ of all oral malignancies (3,11-13). However, our finding was consistent with that of Ajayi et al. (8) who reported that OSCC accounts for $44 \%$ of all oral malignancies. The reason for the wide disparity in the relative frequency of OSCC in this study compared to most other studies is not immediately apparent, but subtle difference in aetiology and predisposing factors are suggested.

The tongue is generally regarded as the commonest site of occurrence for OSCC. Santos et al. (14) suggested that consumption of alcohol from an early age may account for up to $40 \%$ of OSCC in the tongue as reported in their study in Brazil. Choi et al. (15) from Korea, Dimba et al. (16) from Kenya and Iamaroon et al. (17) from Thailand also reported $20.4 \%, 20.1 \%$ and $42.8 \%$ occurrence of OSCC in the tongue respectively. However, results from this present study found that the mandibular mucosa with $26.4 \%$ of cases was the most common site while only $9.2 \%$ occurred in the tongue which was in agreement with studies by Chidzonga et al. (3) and Effiom et al. (18) who reported highest incidence in the mandibular gingiva with values of $21.1 \%$ and $31.8 \%$ in mandibular gingiva respectively. The reason for the relatively high rate of occurrence of OSCC in the mandibular mucosa, the floor of mouth and tongue has been related to the fact that carcinogens in tobacco, alcohol, or foods dissolve in saliva and tend to pool in gravity dependent areas of the mouth (18). The reason for the disparities in the occurrence of OSCC in the mandibular mucosa, the tongue and floor of mouth from different studies, however, needs to be further investigated. The Lip is an uncommon site for OSCC in blacks (18) because of the protective effect of melanin and this is confirmed in this study with only $3.6 \%$ OSCC occurring in the Lip. Santos et al. (14) reported a $31.6 \%$ occurrence in the lower lip and thought that this might be due to the high exposure of their patients to sunlight radiation as the region of study was in close proximity to the equatorial line.

In the present study, the finding of a peak age incidence for OSCC in the 60-69 age group was in consonance with reports that OSCC occurred in older patients. Also, only $17.3 \%$ of cases were seen below 40 years of age. This seems to confirms the long-held view that OSCC is seen more in older people as reported in several previous studies (19-22). On the contrary, a study by Effiom et al. in Lagos found a peak age incidence in the 40-49 age group and $40 \%$ occurrence of OSCC below the age of 40 years.
The well differentiated OSCC with $48.3 \%$ of cases was the most common histology grade while the poorly differentiate grade with $14.4 \%$ was the least common in this study. This was in agreement with previous studies that found well differentiated OSCC to be the most common histologic grade and the poorly differentiated grade to be the least (3). On the contrary, Effiom et al. found the poorly differentiate grade $(47.6 \%)$ to be the commonest and the moderately differentiated (19.7\%) as the least common.

This multicentre study showed that OSCC is more common in males, most commonly seen in the 60-69 age group and the commonest site of occurrence was the mandibular mucosa. The well differentiated OSCC was the most common histology sub-type. However, the differences between some of our findings and some previous studies from Nigeria, such as peak age of occurrence and the most common histologic sub-type, need further investigation.

\section{References}

1. Landis SH, Murray T, Bolden S, Wingo PA. Cancer statistics, 1999. CA Cancer J Clin. 1999;49:8-31,1.

2. Perreira MC, Oliveira DT, Landman G, Kowaslski LP. Histologic subtypes of oral squamous cell carcinoma: prognostic relevance. J Can Den Assoc. 2007;73:339-44.

3. Chidzonga MM, Mahomva L. Squamous cell carcinoma of the oral cavity, maxillary antrum and lip in a Zimbabwean population: A descriptive study. Oral Oncol. 2006;42:184-9.

4. Attar E, Dey S, Hablas A, Seifeldin IA, Ramadan M, Rozek LS, Soliman AS. "Head and Neck Cancer in a developing Country: a Population-Based Perspective Across 8 Years," Oral Oncol. 2010;46:591-96. 5. Ajayi OF, Adeyemo WL, Ladeinde MO, Ogunlewe MO, Effiom OA, Omitola OG, et al. Primary malignant neoplasms of orofacial origin: a retrospective review of 256 cases in a Nigerian tertiary hospital. Int. J. Maxillofac. Surg. 2007;36:403-8.

6. Otoh EC, Johnson NW, Olasoji HO, Danfillo IS, Adeleke OA. Intra-oral carcinoma in Maiduguri, North- eastern Nigeria. Oral Dis. 2005; 11:379-85

7. Johnson NW. Orofacial neoplasms: Global epidemiology, risk factors and recommendations for research. Int Dent J. 1991;41:365-75.

8. Davis S, Severson RK. Increasing incidence of oral cancer of tongue in United States among young adults. Lancet 1987;11:910-11.

9. Shiboski CH, Schmidt BL, Jordan RC. Tongue and tonsil carcinoma: increasing trends in the US population age 20-44 years. Cancer. 2005;103:1843-9.

10. Parkin DM, Pisani P, Ferlay J. Estimates of the worldwide incidence of sixteen major cancers. Int J Cancer. 1993;54:594-606.

11. Mehrotra R, Yadav S. Oral squamous cell carcinoma: etiology, pathogenesis and prognostic value of genomic alterations. Indian $\mathrm{J}$ Cancer. 2006;43:60-6.

12. Chen J, Katz RV, Krutchkoff DJ: Intraoral squamous cell carcinoma: Epidemiologic patterns in Connecticut for 1935 to 1985. Cancer. 1990;66:1288-96.

13. Sargeran K, Murtomaa H, Safavi SMR, et al: Malignant oral tumours in Iran: Ten-year analysis on patient and tumor characteristics of 1042 patients in Tehran. J Craniofac Surg. 2006;17:1230-3.

14. Santos HB, dos Santos TK, Paz AR, Cavalcanti YW, Nonaka CF, Godoy GP, et al. Clinical findings and risk factors to oral squamous cell carcinoma in young patients: A 12-year retrospective analysis. Med Oral Patol Oral Cir Bucal 2016;1:e151-6.

15. Choi KK, Kim MJ, Yun PY, Lee JH, Moon HS, Lee TR et al. Independent prognostic factors of 861 cases of oral squamous cell carcinoma in Korean adults. Oral Oncol. 2006;42:208-17. 
16. Dimba EA, Gichana J, Limo AK, Wakoli KA, Chindia ML, Avange DO. An audit of oral diseases at a Nairobi centre, 2000-2004. Int Dent J. 2007;57:439-44.

17. Iamaroon A, Pattanaporn K, Pongsriwet S, Wanachantarak S, Prapayasatok S, Jittidecharak S, et al. Analysis of 587 cases of oral squamous cell carcinoma in northern Thailand with a focus on young people. Int J Oral Maxillofac Surg. 2004;33:84-8.

18. Effiom OA, Adeyemo WL, Omitola OG, Ajayi OF, Emmanuel MM, Gbotoloroun OM. Oral squamous cell carcinoma: a clinicopathologic review of 233 cases in Lagos, Nigeria. J Oral Maxillofac Surg. 2008;66:1595-9.

19. Andisheh-Tadbir A, Mehrabani D, Heydari ST. Epidemiology of squamous cell carcinoma of the oral cavity in Iran. J Craniofac Surg. 2008;196:1699-702.

20. Otoh EC, Johnson NW, Olasoji HO, Danfillo IS, Adeleke OA. Intra-oral carcinomas in Maiduguri, north-eastern Nigeria. Oral Dis. 2005;116:379-85.

21. Howell RE, Wright BA, Dewar R. Trends in the incidence of oral cancer in Nova Scotia from 1983 to 1997. Oral Surg Oral Med Oral Pathol Oral Radiol Endod. 2003;95:205-12.

22. Marocchio LS, Lima J, Sperandio FF, Corrêa L, de Sousa SO. Oral squamous cell carcinoma: an analysis of 1,564 cases showing advances in early detection. J Oral Sci. 2010;52:267-73.

Acknowledgements

This is to acknowledge the following for contributing data from their centres:

Dr Olufemi Gbenga OMITOLA. Department of Oral Pathology and Biology, University of Port Harcourt, Nigeria.

Dr Olujide Oladele SOYELE. Department of Oral Maxillo-facial Surgery and Oral Pathology, Obafemi Awolowo University, Ile-Ife, Nigeria.

Dr Adetokunbo OLAWUYI. 2Department of Oral and Maxillofacial Pathology \& Biology, Lagos University Teaching Hospital (LUTH) Nigeria.

Dr Benjamin FOMETE. Maxillofacial Surgery Departments, Ahmadu Bello University Teaching Hospital, Zaria, Nigeria.

\section{Conflict of Interest}

The Authors declare no conflict of Interest as study was entirely selffunded. 